\title{
Selective growth of GaN nanorods on the top of GaN stripes
}

\author{
Yeonsu Yu, Junhyeong Lee, Hyungsoo Ahn, Kisam Shin*, Yincheng He* and Min Yang ${ }^{\dagger}$ \\ Department of Applied Sciences, Korea Maritime and Ocean University, Busan 606-791, Korea \\ *School of Nano and Advanced Materials Engineering, Changwon National University, Changwon 641-773, Korea \\ (Received June 27, 2014)
}

(Revised July 18, 2014)

(Accepted July 21, 2014)

\begin{abstract}
GaN}$ nanorods were grown on the apex of $\mathrm{GaN}$ stripes by three dimensional selective growth method. $\mathrm{SiO}_{2}$ mask was partially removed only on the apex area of the GaN stripes by an optimized photolithography for the selective growth. Metallic $\mathrm{Au}$ was deposited only on the apex of the GaN stripes and a selective growth of GaN nanorods was followed by a metal organic vapor phase epitaxy (MOVPE). We confirmed that the shape and size of the GaN nanorods depend on growth temperature and flow rates of group III precursor. GaN nanorods were grown having a taper shape which have sharp tip and triangle-shaped cross section. From the TEM result, we confirmed that threading dislocations were rarely observed in $\mathrm{GaN}$ nanorods because of the very small contact area for the selective growth. Stacking faults which might be originated from a difference of the crystal facet directions between the GaN stripe and the GaN nanorods were observed in the center area of the GaN nanorods.
\end{abstract}

Key words GaN, GaN nanorod, GaN stripe, MOVPE, Nanostructure

\section{GaN stripe 꼭지점 위의 $\mathrm{GaN}$ 나노로드의 선택적 성장}

유연수, 이준형, 안형수, 신기삼*, Yincheng $\mathrm{He}^{*}$, 양민 ${ }^{\dagger}$

한국해양대학교 응용과학과, 부산, 606-791

*창원대학교 나노신소재공학과, 창원, 641-773

(2014년 6월 27일 접수)

(2014년 7월 18일 심사완료)

(2014년 7월 21일 게재확정)

요 약 3차원적 선택적 결정 성장 방법에 의해 $\mathrm{GaN}$ stripe 구조의 꼭지점 부분에만 $\mathrm{GaN}$ 나노로드를 성장하였다. $\mathrm{GaN}$ stripe의 꼭지점 부분의 $\mathrm{SiO}_{2}$ 만을 최적화된 포토리소그라피 공정을 이용하여 제거하고 이를 선택적 결정 성장을 위한 마스 크로 사용하였다. $\mathrm{SiO}_{2}$ 가 제거된 꼭지점 부근에만 $\mathrm{Au}$ 금속을 증착하고, metal organic vapor phase epitaxy(MOVPE) 방법에 의해 $\mathrm{GaN}$ stripe의 꼭지점 부분에만 $\mathrm{GaN}$ 나노로드의 선택적 성장을 실시하였다. $\mathrm{GaN}$ 나노로드의 형상과 크기는 결정 성 장 온도와 III족 원료의 공급량에 의해 변화가 있음을 확인하였다. Stripe 꼭지점에 성장된 $\mathrm{GaN} \mathrm{나노로드는} \mathrm{단면이} \mathrm{삼각형}$ 형태를 가지고 있으며 끝으로 갈수록 점점 폭이 좁아지는 테이퍼 형상을 가지며 성장되었다. TEM 관측 결과, 매우 좁은 영역에서만 선택적 결정 성장이 이루어졌기 때문에 $\mathrm{GaN}$ 나노로드에서 관통전위(threading dislocations)는 거의 관찰되지 않 음을 확인하였다. 선택성장이 시작되는 부분의 결정면과 $\mathrm{GaN}$ 나노로드의 성장방향의 결정면 방향의 차이에 기인하는 적층 결함(stacking faults)들이 $\mathrm{GaN}$ 나노로드의 중심영역에서 생성되는 것을 관찰할 수 있었다.

\section{1. 서 론}

$\mathrm{GaN}$ 는 뛰어난 발광 특성과 우수한 열 전도도 그리고 화학반응과 방사선 노출에 견고하기 때문에 광소자, 고

\footnotetext{
Corresponding author

Tel: +82-51-410-4782

Fax: +82-51-404-3986

E-mail: myang@kmou.ac.kr
}

속, 고온 및 고출력을 필요로 하는 전자소자에 이르기 까지 다양하게 응용할 수 있어서 $\mathrm{GaN}$ 를 기반으로 하는 $\mathrm{III}-\mathrm{V}$ 족 질화물 반도체에 관한 연구가 진행되고 있다[13]. 나노 및 마이크로 크기의 $\mathrm{GaN}$ 의 1 차원 구조물(나노 와이어, 나노로드)은 질화물 반도체를 기반으로 하는 여 러 가지 소자로 응용이 가능해 많은 연구 결과들이 발 표되고 있다[4-7]. 최근에는 불합치 전위(dislocation)와 변형(strain)이 없는 나노크기의 $\mathrm{GaN}$ 피라미드구조물 
(pyramidal hillocks)[8]이나 주상구조물(columnar structure) $[9,10]$ 이 얻어진다고 발표되고 있다. 나노로드를 성장 할 때 대부분 chemical vapor transport(CVT), hydride vapor phase epitaxy(HVPE), molecular beam epitaxy (MBE) 그리고 metal organic vapor phase epitaxy (MOVPE) 결정 성장방법을 이용하여 $\mathrm{GaN}$ 기반의 나노 구조를 형성하고 있다. 일반적으로 나노로드의 기술은 2 차원 성장을 기반으로 촉매를 이용한 무작위 성장 이거 나[11] 혹은 복잡한 건식 식각 공정을 통한 위치 제어를 해야 했다. 자발적으로 형성되는 나노구조들은 밀도나 위치를 제어하는 것이 용이하지 않고, 나노로드의 끝 부 분에 촉매로써 작용된 금속이 남기 때문에 후속 공정을 위해서는 이 금속을 제거해야만 하는 공정이 다시 필요 하다는 문제가 있다. 건식 식각 공정을 이용하여 나노구 조를 형성하는 경우, 나노크기의 마스크패턴 제작 및 건 식 식각 공정의 미세 제어 등을 포함하는 복잡한 공정과 정이 필요하다는 문제점들이 있다. 따라서 비교적 간단 한 공정을 이용하는 한편, 나노구조의 위치 제어를 효율 적으로 할 수 있는 결정 성장 기술의 개발이 필요할 것 으로 생각한다. 한편, $\mathrm{GaN}$ 나노구조를 초소형 광 공진 기나 그 밖의 광소자 그리고 집적형 네트워크 시스템 등 에 이용하기 위해서는 평면에서의 위치뿐만 아니라 높이 까지도 제어가 가능하며 $\mathrm{GaN}$ 나노로드의 성장 방향의 제어가 가능한 3 차원적인 성장 기반의 $\mathrm{GaN}$ 나노로드 구조의 성장이 매우 중요하다. 본 저자들은 $\mathrm{GaN}$ 피라미 드 구조의 꼭지점 위에 습식 에칭 공정만을 이용하여 3 차원적인 위치 제어가 가능한 $\mathrm{GaN}$ 나노로드 결정구조 를 선택적으로 결정 성장할 수 있음을 발표한 바 있다 [12]. 본 연구에서는 삼각형 단면을 가지는 $\mathrm{GaN}$ stripe 구조의 꼭지점 영역을 이용하여 성장온도 및 원료공급 비율 등의 결정 성장 조건들의 변화가 $\mathrm{GaN}$ 나노로드의 형상에 어떠한 영향을 미치는 가에 대해서 확인하고, 선 택적 결정 성장이 이루어지는 경계 영역에서의 결정 결 함 분포에 대해서 알아보았다. 3 차원적으로 위치 제어가 가능한 선택적 결정 성장을 위하여 $\mathrm{GaN}$ stripe 구조를 우선 형성하고, 그 위에 선택적 성장을 위한 $\mathrm{SiO}_{2}$ 마스 크를 증착하였다. 최적화된 포토리소그라피 공정을 통해 $\mathrm{GaN}$ stripe 구조의 꼭지점 부분만 $\mathrm{SiO}_{2}$ 막을 제거한 후, $\mathrm{Au}$ 를 증착하여 이 영역에서만 $\mathrm{GaN}$ 나노로드 결정구조 들이 선택적으로 성장될 수 있도록 하였다. 결정성장은 metal organic vapor phase epitaxy(MOVPE) 결정 성장 방법을 이용하여 상압에서 실시하였으며, TMG(trimethylgallium)와 암모니아를 III족 원료와 V족 원료로서 각각 이용하였다. 결정 성장 조건에 따른 $\mathrm{GaN}$ 나노로드의 미 세구조들의 형상 변화는 field emission scanning electron microscope(FE-SEM)을 이용해 관찰하였다. $\mathrm{GaN}$ 나노 로드들이 형성되기 시작하는 영역의 구조적 특성과 결정
결함들을 확인하기 위하여 $\mathrm{X}$-선 회절 및 transmission electron microscope(TEM) 분석을 실시하였다.

\section{2. 실험방법}

본 연구에서는 undoped $\mathrm{GaN}$ 기판 위에 $\mathrm{RF}$ sputter를 이용하여 $\mathrm{SiO}_{2}$ 막을 증착한 후에 포토리소그라피 공정 을 통하여 폭 $3 \mu \mathrm{m}$, 주기 $10 \mu \mathrm{m}$ 의 stripe 패턴을 (1100) 방향에 평행하도록 형성하였다. 패턴이 형성된 기판 위 에 MOVPE 결정성장 방법을 이용하여 단면이 삼각형인 $\mathrm{GaN}$ stripe 구조를 형성하였다. GaN stripe 구조 형성이 완료된 후에 다시 $\mathrm{SiO}_{2}$ 막을 전체 표면에 증착하였으며, 꼭지점 부분의 $\mathrm{SiO}_{2}$ 만을 제거하기 위하여 포토리소그 라피 공정을 다음과 같이 실시하였다. 우선, 감광액 (photoresist: AZ5214)을 $3000 \mathrm{rpm}$ 으로 시료 전면에 도 포하고 $90^{\circ} \mathrm{C}$ 에서 10 분간 hot plate 위에서 baking하였다. 그 후, 마스크가 없는 상태에서 노광을 실시(235 watt, 7초)한 뒤, 현상액(MIF 500) 속에서 3초 동안 반응시켜 꼭지점 부분만 감광 물질을 제거하였다. 마지막으로 꼭 지점 부분에 노출된 $\mathrm{SiO}_{2}$ 막을 buffered oxide etchant (BOE)를 이용하여 제거하였다. 위의 공정이 모두 완료 된 후 시료 위에 E-beam evaporator를 이용하여 $\mathrm{Au}$ 를 $5 \mathrm{~nm}$ 증착하고, lift-off 공정을 이용하여 $\mathrm{GaN}$ stripe 꼭 지점 위에만 $\mathrm{Au}$ 금속이 남도록 하였다. $\mathrm{GaN}$ stripe 구 조의 꼭지점 부근에만 금속 증착이 완료된 시료를 다시 MOVPE 반응관에 장착하여 $\mathrm{GaN}$ stripe 구조의 꼭지점 부분에 $\mathrm{GaN}$ 나노로드 구조를 선택적으로 성장하였다. 분위기 가스로는 $\mathrm{N}_{2}$ 를 사용하였으며, 암모니아의 유량과 성장 시간은 $6.70 \times 10^{-2} \mathrm{~mol} / \mathrm{min}$ 과 20 분으로 각각 일정 하게 유지하면서 $\mathrm{TMG}$ 의 양은 $22.92 ~ 65.50 \mu \mathrm{mol} / \mathrm{min}$, 성장 온도는 $820 ~ 880^{\circ} \mathrm{C}$ 의 범위에서 변화를 주며 $\mathrm{GaN}$ 나노로드 구조를 성장하였다.

\section{3. 결과 및 고찰}

$\mathrm{TMGa}$ 공급량의 변화에 대한 $\mathrm{GaN}$ 나노로드 구조들의 모습을 Fig. 1에 나타내었다. 성장 온도는 $820^{\circ} \mathrm{C}$, 성장 시간은 모두 20 분으로 일정하게 하였다. $\mathrm{TMGa}$ 공급량 은 각각 $22.92,32.75$ 그리고 $65.50 \mu \mathrm{mol} / \mathrm{min}$ 으로 변화 를 주면서 $\mathrm{GaN}$ 나노로드를 형성하였다. 세 가지 경우의 공통적인 특징을 살펴보면, 우선적으로 $\mathrm{GaN}$ stripe의 꼭 대기 영역을 따라서 1 차원적으로 불규칙한 선형결정이 형성되면서 동시에 특정 방향으로 삼각형 형태의 단면을 가지는 $\mathrm{GaN}$ 나노로드들이 형성되고 있으며, $\mathrm{GaN}$ 나노 로드 길이 방향의 끝부분으로 갈수록 굵기가 가늘어지는 

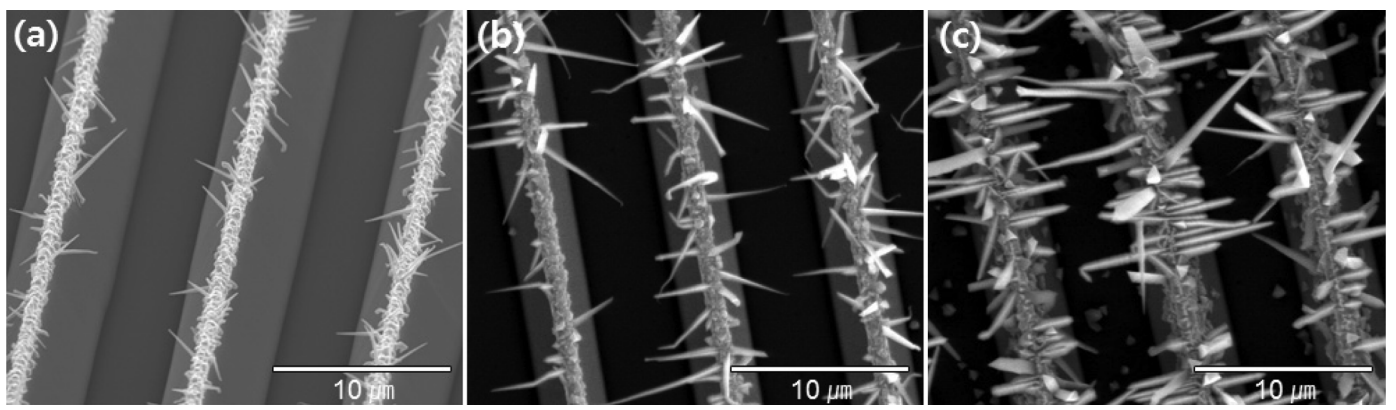

Fig. 1. SEM images of the GaN nanostructures depending on the flow rates of TMG source (a) $22.92 \mu \mathrm{mol} / \mathrm{min}$ (b) $32.75 \mu \mathrm{mol} / \mathrm{min}$ (c) $65.50 \mu \mathrm{mol} / \mathrm{min}$.

경향을 보이고 있다. $\mathrm{TMGa}$ 의 공급량이 $22.92 \mu \mathrm{mol} / \mathrm{min}$ 인 경우(Fig. 1(a)) 길이 $1 \sim 2.5 \mu \mathrm{m}$, 굵기 $100 \mathrm{~nm}$ 이하의 $\mathrm{GaN}$ 나노로드들이 주로 $(10 \overline{10})$ 및 $(01 \overline{1} 0)$ 방향으로 성 장되는 것을 확인할 수 있었다. $\mathrm{TMGa}$ 공급량이 32.75 $\mu \mathrm{mol} / \mathrm{min}$ 로 증가한 경우 $\mathrm{GaN}$ 나노로드의 길이와 굵기 는 각각 4 5 $\mu \mathrm{m}, 250 \mathrm{~nm}$ 로 증가 하였다. 그리고 65.50 $\mu \mathrm{mol} / \mathrm{min}$ (Fig. $1(\mathrm{c})$ )의 경우에는 길이와 굵기가 각각 5 $8 \mu \mathrm{m}, 300 \mathrm{~nm}$ 로 증가하였으며, (1010) 및 $(01 \overline{1} 0)$ 방향에 비해서 (1120)방향으로 성장되는 $\mathrm{GaN}$ 나노로드의 수가 상대적으로 증가하는 경향을 보이고 있다.

$\mathrm{TMGa}$ 양을 $22.92 \mu \mathrm{mol} / \mathrm{min}$ 로 고정시키고 성장 온도 를 $850^{\circ} \mathrm{C}$ 와 $880^{\circ} \mathrm{C}$ 까지 높인 경우의 결과를 Fig. 2 에 나 타내었다. $850^{\circ} \mathrm{C}$ 에서 성장한 $\mathrm{GaN}$ 나노로드들(Fig. 2(a)) 은 평균 길이와 굵기가 각각 $2 \sim 3 \mu \mathrm{m}, 150 \mathrm{~nm}$ 로서 $820^{\circ} \mathrm{C}$ 에서 성장한 경우(Fig. 1(a))에 비하여 $\mathrm{GaN}$ 나노로드의 길이와 굵기가 약간 증가하는 것을 확인할 수 있었으며, $\mathrm{GaN}$ 나노로드의 방향도 거의 대부분 (1120) 방향으로 형성되고 있음을 알 수 있었다. $\mathrm{GaN}$ 결정 성장의 경우, 성장 온도에 따라서 결정면 방향들의 표면에너지 차이에 의해서 각 결정면 들의 성장 속도에 차이가 생기고 이에 따라서 성장된 $\mathrm{GaN}$ 결정 구조들의 형상에 변화가 생기 는 것이 일반적이다. 성장온도를 $820^{\circ} \mathrm{C}$ 에서 $850^{\circ} \mathrm{C}$ 로 증 가한 경우, 성장온도가 높아짐에 따라 (1010) 및 $(01 \overline{1} 0)$
결정면보다는 $(11 \overline{2} 0)$ 결정면 방향의 표면에너지가 점차 낮아져서 $(11 \overline{2} 0)$ 방향으로의 $\mathrm{GaN}$ 나노로드 성장이 우 세해지는 것으로 판단된다. 한편, $880^{\circ} \mathrm{C}$ 까지 성장 온도 를 높인 경우(Fig. 2(b))에는 나노로드의 형상은 보이지 않고, 육각 판상 형태를 포함하는 불규칙한 $\mathrm{GaN}$ 입자들 만 형성되는 것을 확인할 수 있었다. 일반적으로, $\mathrm{Au}$ 와 같은 금속 촉매를 사용하여 저온 및 2차원적 평면 성장 을 실시하는 경우 vapor-liquid-solid(VLS) 성장 기구에 의해 $\mathrm{GaN}$ 나노로드는 불규칙한 방향성, 일정한 굵기 그 리고 끝 부분의 금속 뭉침 현상들을 보여주는 것으로 알 려져 있다[13-16]. 본 실험에서는 금속 촉매로서 $\mathrm{Au}$ 를 사용하였지만 $\mathrm{GaN}$ 나노로드의 방향성을 제어하기 위한 목적으로 $820^{\circ} \mathrm{C}$ 이상으로 성장온도를 높이고, 또한 매우 좁은 영역에서의 선택적 결정 성장을 실시하였기 때문에 VLS 성장 기구가 아닌 다른 성장 기구에 의해서 방향성 이 뛰어나고 끝이 뾰족한 $\mathrm{GaN}$ 나노로드들이 형성된 것 으로 판단한다. 끝이 뾰족하고 방향성이 우수한 $\mathrm{GaN}$ 나 노로드들의 형성의 가능한 성장 기구에 대해 알아보기 위하여 $820^{\circ} \mathrm{C}$ 에서 성장된 $\mathrm{GaN}$ 나노로드(TMGa: 22.92 $\mu \mathrm{mol} / \mathrm{min})$ 에 대하여 X-ray 회절 분석을 실시하였다. Xray 회절 스캔방법은 $\theta-2 \theta$, 가속전압은 $30 \mathrm{kV}$, 그리고 $\mathrm{X}$-선의 파장은 $\mathrm{Cu}$ 의 $\mathrm{K} \alpha_{1}$ 에 대응하는 $1.5405 \AA$ 이었으 며, X-ray 회절 결과를 Fig. 3에 보였다.

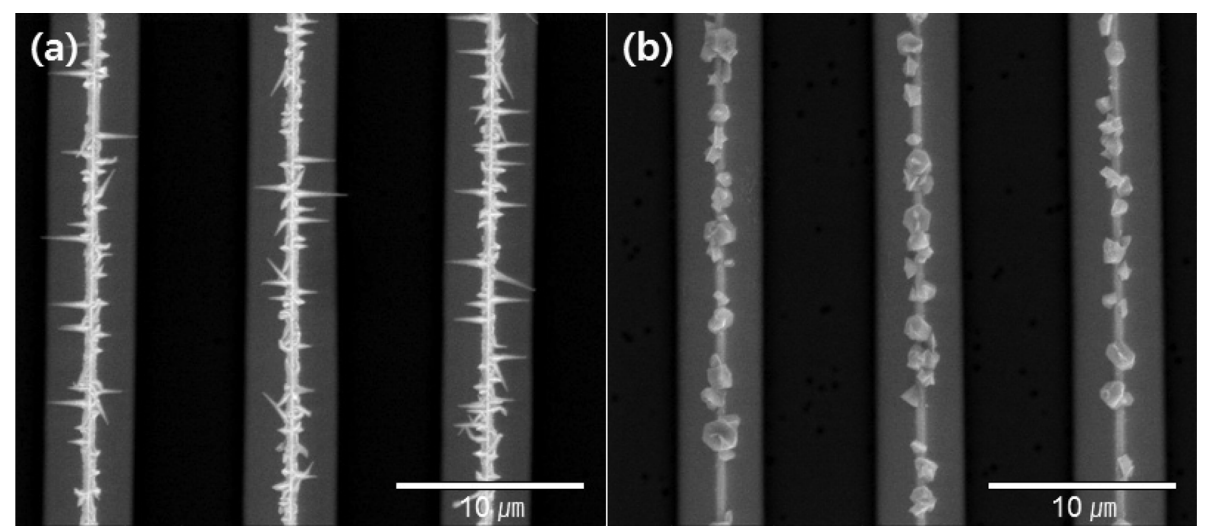

Fig. 2. SEM images of the GaN nanostructures depending on the growth temperature (a) $850^{\circ} \mathrm{C}$ (b) $880^{\circ} \mathrm{C}$. 


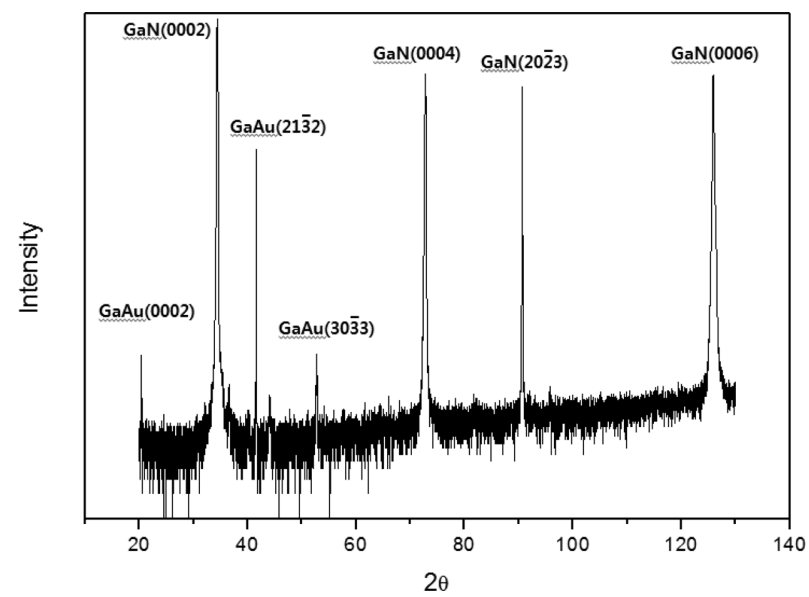

Fig. 3. Result of x-ray diffraction of the selectively grown $\mathrm{GaN}$ rods on the apex of $\mathrm{GaN}$ stripe.

(0002)와 (2023) $\mathrm{GaN}$ 결정면들에 의한 피크와 함께 $\mathrm{Ga}$ 과 $\mathrm{Au}$ 의 화합물 형태인 $\mathrm{Ga}_{2} \mathrm{Au}_{7}$ (0002), $\mathrm{Ga}_{2} \mathrm{Au}_{7}$ (21) 32$)$ 그리고 $\mathrm{Ga}_{2} \mathrm{Au}_{7}$ (30)33)면에서의 피크들이 관찰 되었다. 어떤 성장 기구에 의해서 이들 $\mathrm{GaAu}$ 화합물이 $\mathrm{GaN}$ 나노로드의 형성에 영향을 주는 가에 대해서는 향 후 더욱 다양하고 정밀한 분석을 실시할 예정이지만, 현 재로서는 이들 $\mathrm{GaAu}$ 화합물이 VLS와는 다른 메커니즘 을 통해 $\mathrm{GaN}$ 나노로드가 형성될 수 있도록 결정 성장 초기의 핵생성 단계에 영향을 주었을 것으로 추측된다.

Fig. 4에는 $\mathrm{GaN}$ stripe 구조 꼭지점 위의 $\mathrm{GaN}$ 나노로 드의 TEM 이미지와 나노로드의 영역별 SADP(selected area diffraction patterns) 결과를 나타내었다. SADP에 의해 관찰된 $\mathrm{GaN}$ 나노로드는 단결정으로 잘 성장되었 으며, (1120) 방향으로 조밀육방구조 $(\mathrm{HCP})$ 를 가지고 성 장됨을 확인할 수 있었다. $\mathrm{GaN}$ 나노로드의 중심 영역 근방(Fig. 4(a)의 1, 2 영역)에서는 c축 방향으로의 압축 변형(compressive strain)이 발생함을 확인하였다. 이러한 변형(strain)의 원인으로는 선택적 결정 성장이 시작되는 결정면은 $\mathrm{GaN}$ stripe의 $(11 \overline{2} 2)$ 결정면인 반면에 나노로 드의 성장은 (0002) 결정면과 (1120) 결정면을 포함하는 구조로 형성되고 있기 때문에 이들 각 결정면들의 원자 배열의 차이에 의해서 발생하는 것으로 판단한다. 한편, 선택적 결정성장을 위한 $\mathrm{GaN}$ stripe과 $\mathrm{GaN}$ 나노로드의 경계 지점으로부터 멀어질수록 $\mathrm{GaN}$ 나노로드의 변형 (strain)은 점차적으로 완화되며 $\mathrm{GaN}$ 나노로드 중심에서 약 $1500 \mathrm{~nm}$ 떨어진 영역(Fig. 4(a)의 4 영역) 에서는 완 전히 완화되는 경향을 보이고 있다.

Fig. 5에는 $\mathrm{GaN}$ stripe의 꼭지점 위에 성장시킨 $\mathrm{GaN}$ 나노로드의 단면 TEM 사진을 보였다. Fig. 5의 A 영역 은 undoped $\mathrm{GaN}$ 기판과 $\mathrm{GaN}$ stripe이 성장된 계면부 분이다. $\mathrm{GaN}$ stripe 영역에 기판으로부터 전이된 관통전 위(threading dislocation) 이외에도 stacking faults(SF)들 이 많이 발생하였음을 알 수 있는데, 이는 GaN stripe의 성장을 위한 MOVPE 성장 조건들이 최적화 되지 않았 기 때문인 것으로 추측된다. 한편, $\mathrm{GaN}$ stripe 꼭지점에 선택적 결정 성장에 의해 형성된 $\mathrm{GaN}$ 나노로드 영역에 는 관통전위(threading dislocation)들을 관찰할 수 없었 는데, 이는 매우 좁은 $\mathrm{GaN}$ stripe의 꼭지점 영역에서만 선택적 결정 성장이 가능하도록 $\mathrm{SiO}_{2}$ 마스크를 제작하 여 관통전위가 $\mathrm{GaN}$ 나노로드까지 진행하는 것을 효과 적으로 막을 수 있었기 때문인 것으로 판단한다. 한편, 관통전위(threading dislocations)는 관찰되지 않았지만 뒤에서 설명하게 되는 바와 같이, $\mathrm{GaN}$ 나노로드 중심 영역에 많은 적층 결함(stacking fault)들이 발생하는 것 을 관찰 할 수 있었다. $\mathrm{GaN}$ 나노로드 중심 영역(Fig. 5 (b)의 B 영역)에서의 적층 결정 결함 분포를 좀 더 확 실하게 확인하기 위하여 역푸리에변환(inverse fast Fourier transform(IFFT)) 분석을 실시하였다.

Fig. 6의 (a)와 (b)는 각각 (0002) 면과 (1120) 면에

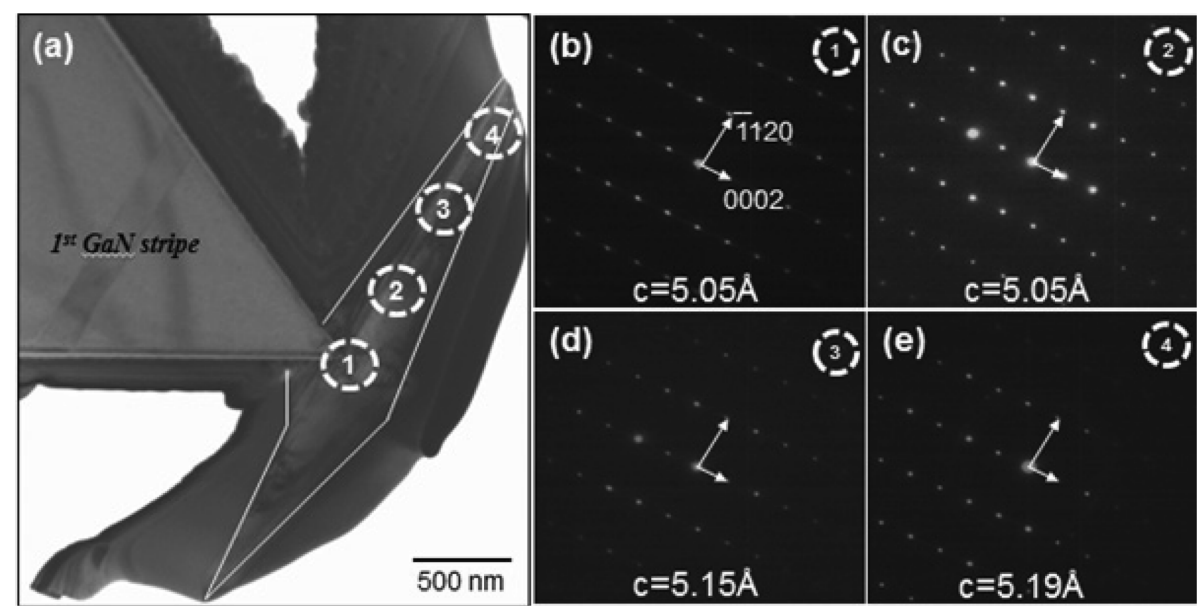

Fig. 4. TEM image of GaN nanorod (a) and selected area diffraction patterns (SADP) (b, c, d, e) at different positions in the GaN nanorod. 


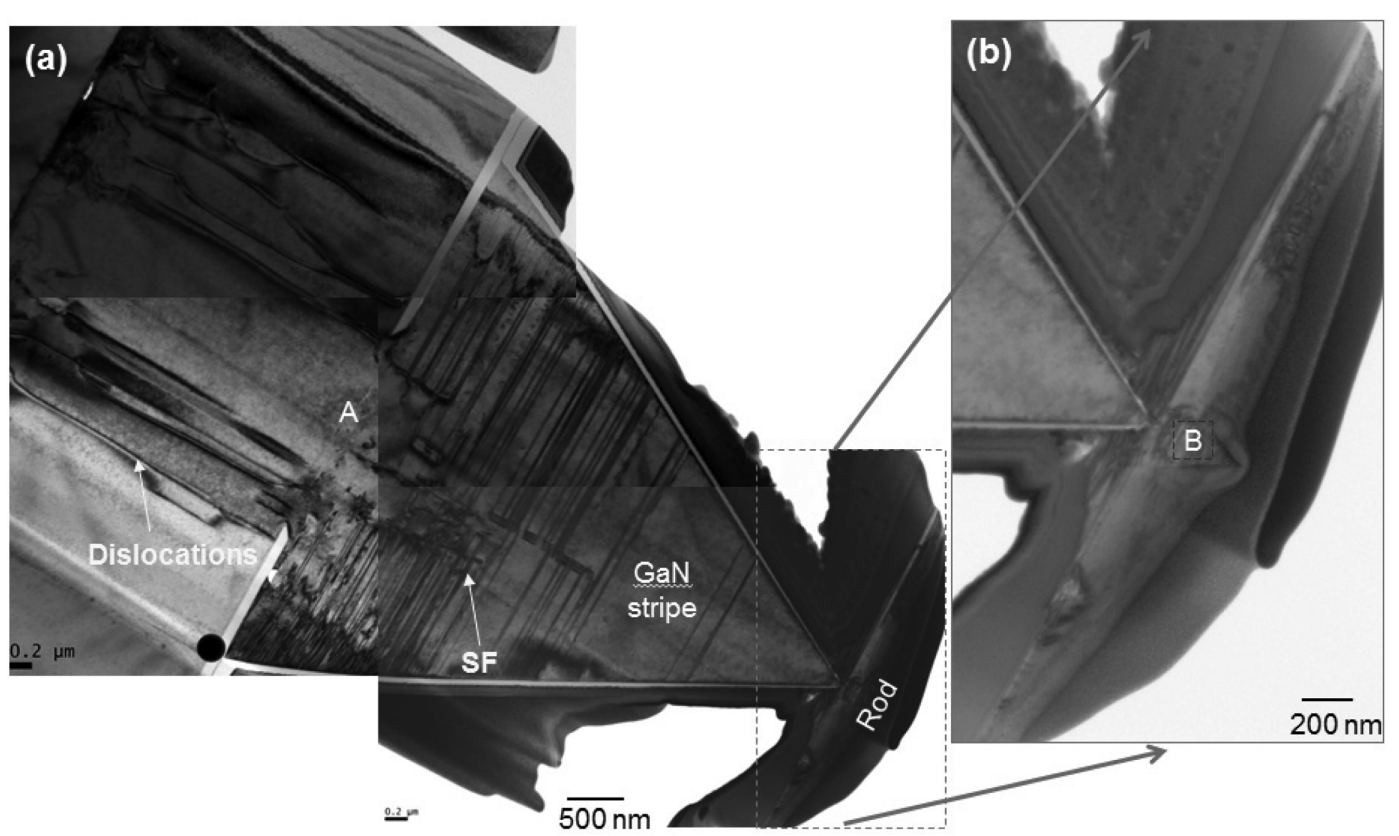

Fig. 5. TEM image of the selectively grown GaN nanorod on the apex of $\mathrm{GaN}$ stripe (a) overall structure including substrate (b) enlarged image around the apex of the GaN stripe.

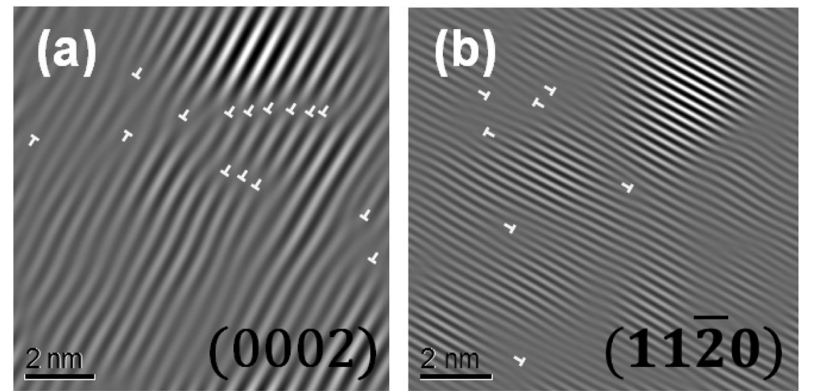

Fig. 6. IFFT images of the GaN rod (a) (0002) plane, (b) (1120) plane.

대한 역푸리에 변환 결과이다. $\mathrm{GaN}$ 나노로드의 중심영 역은 $\mathrm{GaN}$ stripe 구조로부터 직접적인 영향을 받으며, 선택적 결정 성장이 시작되는 영역 부근이기 때문에 비 교적 높은 밀도의 적층결함을 보이고 있다. 그림에 적층 결함 부분들은 " $\mathrm{T}$ " 모양으로 표시를 하였는데, $\mathrm{GaN}$ stripe으로부터 직접적인 영향을 받는 c축 성장 면인 (0002) 면에 비해서 측면 성장이 이루어지는 $(11 \overline{2} 0)$ 면 의 적층결함 $(\mathrm{SF})$ 밀도가 비교적 낮음을 확인할 수 있었 다. 적층결함 $(\mathrm{SF})$ 발생 원인은 여러 가지가 있을 수 있 으나, 본 연구에서 제안한 방법에 의하면 앞에서도 언급 한 바와 같이, 선택적 결정 성장이 시작되는 결정면 방 향과 $\mathrm{GaN}$ 나노로드가 성장되는 결정 방향에 차이가 있 는데 이러한 점도 적층결함의 발생에 중요한 원인이 될 수 있을 것으로 판단한다. $\mathrm{GaN}$ 나노로드는 $\mathrm{GaN}$ stripe 의 (11) 2 2) 면에서 초기 성장이 이루어졌음에도 불구하고,

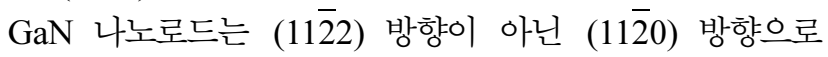

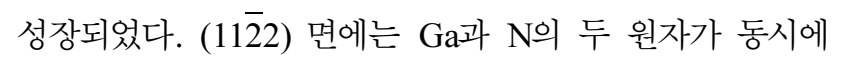
결정단면을 구성하며 반극성 면을 가지는 반면에, (1120) 면은 무극성 면으로 $\mathrm{Ga}$ 과 $\mathrm{N}$ 의 표면 원자들이 지그재그 로 형태로 배열 되어있다. 따라서 두 결정면들의 원자배 열 및 결정면 표면의 퍼텐셜 에너지 장벽의 차이 등에 의해 적층 결함(stacking fault)들이 발생될 수 있을 것으 로 판단된다.

\section{4. 결 론}

$\mathrm{GaN}$ stripe의 꼭지점 영역이라는 특정 위치에 $\mathrm{GaN}$ 나노로드 구조를 형성할 수 있음을 확인하였으며, 방향 과 크기의 제어는 III족 원료의 공급량과 성장온도의 조 절에 의해서 가능함을 확인하였다. III족 원료의 공급량 에 비례하여 $\mathrm{GaN}$ 나노로드의 크기가 커지는 경향을 보 이며, 성장온도가 $820^{\circ} \mathrm{C}$ 에서 $850^{\circ} \mathrm{C}$ 로 증가한 경우, $(11 \overline{2} 0)$ 방향으로의 $\mathrm{GaN}$ 나노로드 성장이 우세해지는 결 과를 보였다. $\mathrm{Au}$ 를 촉매로 사용하였으나 결정 성장 온 도 및 선택적 성장 영역의 극히 좁은 면적 등을 포함하 는 특정 성장 조건에서는 $\mathrm{VLS}$ 성장기구가 아닌 새로운 성장기구에 의해 $\mathrm{GaN}$ 나노로드의 형성이 가능함을 확 인하였다. $\mathrm{GaN}$ 나노로드 중심영역에서는, 선택적 성장 이 시작되는 $\mathrm{GaN}$ stripe 경사면의 결정면과 $\mathrm{GaN}$ 나노 로드의 성장방향의 차이로 인한 스트레인이 존재하지만

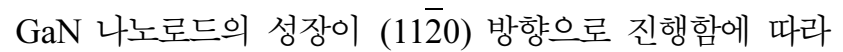
서 스트레인은 점차 완화되며, 중심에서 약 $1500 \mathrm{~nm}$ 거 
리에서 완전히 제거됨을 확인하였다. 또한, $\mathrm{GaN}$ stripe 의 경사면의 결정면 방향과 $\mathrm{GaN}$ 나노로드의 성장방향 의 차이가 $\mathrm{GaN}$ 나노로드 중심 영역의 적층결함들의 발 생원인이 될 수 있음을 제시하였다. $\mathrm{GaN}$ 나노로드 전체 영역에 대한 결정 결함 분포와 발생원인 그리고 $\mathrm{Au}$ 가 $\mathrm{GaN}$ 나노로드 형성 기구에 미치는 영향에 대해서는 보 다 세밀한 분석을 진행중이며 추후 그 결과들에 대해 발 표할 예정이다. 최적화된 결정 성장을 통하여 결함밀도 를 대폭 감소할 수 있도록 결정 성장 기술을 보다 최적 화 한다면, 본 연구에서 제안하는 3 차원 위치제어가 가 능한 $\mathrm{GaN}$ 나노로드 성장 방법은 그의 응용분야가 상당 히 넓을 것으로 기대한다.

\section{감사의 글}

이 논문은 2014년도 정부(교육부)의 재원으로 한국 연구재단의 기초연구사업 지원을 받아 수행된 것임 (2013R1A1A4A01005797).

\section{References}

[ 1 ] K.P. O’Donnell, R.W. Martin and P.G. Middleton, "Origin of luminescence from InGaN diodes", Phys. Rev. Lett. 82 (1999) 237.

[2 ] J.I. Pankove and T.D. Moustakes, "Gallium Nitride II: Semiconductor and semimetals", Academic Press, New York (1999) 57.

[ 3 ] Y. Xia, P. Yang, Y. Sun, Y. Wu, B. Mayers, B. Gates, Y. Yin, F. Kim and H. Yan, "One-dimensional nanostructures: Synthesis, characterization, and applications", Adv. Mater. 15 (2003) 353.

[ 4 ] S. Kobayashi, S. Nonomura, T. Ohmori, K. Abe, S. Hirata, T. Uno, T. Gotoh and S. Nitta, "Optical and electrical properties of amorphous and microcrystalline GaN films and their application to transparent TFT", Appl. Surf. Sci. 113/114 (1997) 480.

[ 5 ] O. Ambacher, J. Smart, J.R. Shealy, N.G. Weimann, K.
Chu, M. Murphy and J. Hilsenbeck, "Two-dimensional electron gases induced by spontaneous and piezoelectric polarization charges in N- and Ga-face AlGaN/GaN heterostructures", J. Appl. Phys. 85 (1999) 3222.

[6] F.A. Ponce and D.P. Bour, "Nitride-based semiconductors for blue and green light-emitting devices", Nature 386 (1997) 351.

[7] H. MorKoc and S.N. Mohammand, "High-luminosity blue and blue-green gallium nitride light-emitting diodes", Science 267 (1995) 51.

[ 8 ] L.T. Romano and T.H. Myers, "The influence of inversion domains on surface morphology in GaN grown by molecular beam epitaxy", Appl. Phys. Lett. 71 (1997) 3486.

[9 ] M. Yoshizawa, A. Kikuchi, N. Fujita, K. Kushi, H. Sasamoto and K. Kishino, "Self-organization of GaN/ $\mathrm{Al}_{0.18} \mathrm{Ga}_{0.82} \mathrm{~N}$ multi-layer nano-columns on (0001) $\mathrm{Al}_{2} \mathrm{O}_{3}$ by $\mathrm{RF}$ molecular beam epitaxy for fabricating $\mathrm{GaN}$ quantum disks", J. Cryst. Growth 189/190 (1998) 138.

[10] I.M. Tiginyanu, V.V. Ursaki, V.V. Zalamai, S. Langa, S. Hubbard, D. Pavlidis and H. Foll, "Luminescence of GaN nanocolumns obtained by photon-assisted anodic etching", Appl. Phys. Lett. 83 (2003) 1551.

[11] Yang, Peidong and Charles M. Lieber, "Nanorod-superconductor composites: A pathway to materials with high critical current densities", Science 273 (1996) 1836.

[12] W.I. Yun, D.W. Jo, J.E. Ok, H.S. Jeon, G.S. Lee, S.K. Jung, S.M. Bae, H.S. Ahn and M. Yang, "Formation of GaN microstructures using metal catalysts on the vertex of GaN pyramids", J. Korean Cryst. Growth Cryst. Technol. 21(3) (2011) 110.

[13] G. Lee, Y.S. Woo, J.E. Yang, D. Lee, C.J. Kim and M.H. Jo, "Directionally integrated VLS nanowire growth in a local temperature gradient", Angewandte Chemie International Edition 48.40 (2009) 7366.

[14] R.S. Wagner and W.C. Ellis, "Vapor-liquid-solidmechanism of single crystal growth", Applied Physics Letters 4(5) (1964) 89.

[15] Y. Wu, Y. Cui, L. Huynh, C.J. Barrelet, D.C. Bell jand C.M. Lieber, "Controlled growth and structures of molecular-scale silicon nanowires", Nano Lett. 4.3 (2004) 433.

[16] S. Kodambaka, J. Tersoff, M.C. Reuter and F.M. Ross, "Diameter-independent kinetics in the vapor-liquid-solid growth of Si nanowires", Physical Review Letters 96.9 (2006) 096105. 